\title{
A inserção da pesquisa em Educação Ambiental na pós-graduação brasileira: o debate a partir do PPGEA/FURG
}

\author{
Vanessa Hernandez Caporlingua ${ }^{1}$
}

Resumo: No VI Encontro de Pesquisa em Educação Ambiental (EPEA), ocorrido em setembro de 2011, debateu-se a inserção da pesquisa na pósgraduação brasileira em mesa-redonda que oportunizou conhecer e refletir sobre diferentes realidades dos programas presentes, os quais apontaram características, desafios e perspectivas para a continuidade da pesquisa em Educação Ambiental no Brasil. O debate problematizou a ambientalização dos currículos, das linhas de pesquisa e das disciplinas de maneira a questionar quais foram, são e serão as mudanças na compreensão da pesquisa em Educação Ambiental. Portanto, este artigo trata de tema debatido durante o evento citado com o propósito de ampliar as reflexões referentes à inserção da pesquisa em Educação Ambiental.

Palavras-chave: Pesquisa. Educação Ambiental. Pós-graduação brasileira.

\section{Inclusion of research on Environmental Education into Brazilian graduate programs: the debate based on the PPGEA/FURG}

Abstract: At the VI Research Meeting on Environmental Education (EPEA), which took place in September 2011, the inclusion of research into the Brazilian graduate programs was discussed in a round-table conference that provided an opportunity to know about and reflect on the different realities of the participating programs, which pointed out characteristics, challenges and perspectives for the continuity of Environmental Education research in Brazil. The debate raised the issue of the greening of curriculum, threads of research and disciplines in order to question what were, are and will be the changes in the understanding of

\footnotetext{
${ }^{1}$ Coordenadora do Programa de Pós-Graduação em Educação Ambiental (PPGEA) da Universidade Federal do Rio Grande (FURG); professora da Faculdade de Direito (FADIR) da FURG; líder do Grupo de Pesquisa Direito e Educação Ambiental GPDEA/CNPq, Rio Grande, Brasil, vanessac@vetorial.net
} 
Environmental Education research. This paper approaches the main theme of that debate aiming to extend the reflections concerning the insertion of Environmental Education research.

Keywords: Research. Environmental Education. Brazilian graduate programs.

\section{La inserción de la investigación en Educación Ambiental en el posgrado brasileño: el debate a partir del PPGEA/FURG}

Resumen: En el VI Encuentro de Investigación en Educación Ambiental (EPEA), ocurrido en septiembre de 2011, se debatió la inserción de la investigación en el posgrado brasileño en mesa-redonda que ofreció la oportunidad de conocer y reflexionar sobre las diferentes realidades de los programas presentes, que apuntaron características, desafíos y perspectivas para la continuidad de la investigación en Educación Ambiental en Brasil. El debate problematizó la ambientalización de los currículos, de las líneas de investigación y de las disciplinas de manera a cuestionar cuáles fueron, son y serán los cambios en la comprensión de la investigación en Educación Ambiental. Por tanto, este artículo trata el tema debatido durante el evento citado con el propósito de ampliar las reflexiones referentes a la inserción de la investigación en Educación Ambiental.

Palabras clave: Investigación. Educación Ambiental. Posgrado brasileño.

\section{Introdução}

Inicialmente agradeço à comissão organizadora pelo convite para participar do VI Encontro de Pesquisa em Educação Ambiental (EPEA) e pela oportunidade ímpar de conhecimento e diálogo com tão importantes representantes da Educação Ambiental, nacional e internacionalmente reconhecidos.

A mesa-redonda intitulada $A$ inserção da pesquisa na pós-graduação brasileira, ocorrida no VI EPEA, em setembro de 2011, foi momento de debate entre representantes de diversos programas de pós-graduação. Pela Coordenação do Programa de Pós-Graduação em Educação Ambiental (PPGEA) da Universidade Federal do Rio Grande (FURG/RS), elaborou-se um texto-base e uma apresentação em slides do primeiro e único Programa de Pós-Graduação em Educação Ambiental do Brasil para iniciar a discussão.

O texto teve como objetivo tratar de forma articulada o histórico do surgimento do PPGEA/FURG e a produção científica realizada durante o processo educativo ambiental de forma a proporcionar o ponto de partida das 
discussões, as quais apontaram características, desafios e perspectivas para a pesquisa em Educação Ambiental.

Muitos trabalhos investigativos sobre a pesquisa brasileira em EA vêm se desenvolvendo nos últimos anos, dos quais se destacam: "As pesquisas sobre educação ambiental no Brasil e as escolas: alguns comentários iniciais", desenvolvido por Fracalanza (2004); "O estado da arte da pesquisa em Educação Ambiental no Brasil", de Reigota (2005), o qual avalia a produção acadêmica brasileira de teses e dissertações em EA no período compreendido entre 1984 e 2002; o trabalho de Lorenzetti e Delizoicov (2007), no qual é analisada a produção em EA proveniente de diversos programas de pós-graduação brasileiros; a pesquisa do Ministério da Educação e Cultura (MEC) (2006) intitulada "Educação na diversidade: o que fazem as escolas que dizem que fazem Educação Ambiental?" é trabalho que também merece destacada referência; por fim, e sem ter a pretensão de esgotar o assunto a respeito de importantes trabalhos já realizados no sentido exposto, ressalta-se o trabalho de Carvalho e Farias (2011), "Um balanço da produção científica em educação ambiental de 2001 a 2009 (ANPEd, ANPPAS e EPEA)", que se preocupa com a legitimação de um conhecimento válido em EA e a autoridade em falar desse campo investigativo.

ssim, este artigo procura tratar de tema que vem sendo debatido a fim de ampliar as reflexões em torno da realidade da pesquisa em Educação Ambiental no Brasil e do papel do educador ambiental nas mais diversas áreas do conhecimento.

\section{O contexto da pesquisa em Educação Ambiental}

O espaço de conhecimento e diálogo proporcionado pelo VI EPEA evidenciou importante debate sobre a inserção da pesquisa em Educação Ambiental na pós-graduação brasileira, pois possibilitou que os participantes do evento expusessem a respeito das pesquisas em Educação Ambiental nos mais diferentes programas de pós-graduação.

Conforme Carvalho e Farias (2011, p. 121), o EPEA já se consolidou como espaço de discussão da pesquisa em Educação Ambiental:

Em todas as suas edições, manteve como objetivos: identificar e analisar as tendências e perspectivas da produção científica sobre EA; criar espaços de apresentação e debate de relatos de pesquisa em EA; dar continuidade ao levantamento do estado da arte da pesquisa em EA no país; e identificar possibilidades teórico-metodológicas significativas para as pesquisas relacionadas com a EA, bem como as prioridades que possam orientar os esforços $\mathrm{e}$ investimentos na área. 
A questão norteadora do debate foi a identidade da Educação Ambiental nos Programas de Pós-Graduação brasileiros, que, mesmo não possuindo explicitados em seus títulos o termo Educação Ambiental, abrigam linhas de pesquisa ou núcleos temáticos na área. Todos geram pesquisa em EA com a consequente publicação de trabalhos e artigos em congressos, eventos e periódicos científicos relativos à área.

Durante o evento, os programas representados, na sua maioria, não pertenciam à área da educação, porém, foi amplamente levado a conhecimento que as pesquisas desenvolvidas são eficazmente articuladas e orientadas por professores que trabalham com a Educação Ambiental, na vinculação com uma disciplina, sublinha, grupo de pesquisa ou projeto.

Notadamente, a pesquisa em EA, por seu caráter transversal e interdisciplinar, está contemplada nas mais diversas áreas do conhecimento, promovendo interfaces e intervenções complexas e contextualizadas com o seu tempo. Nesse sentido, afirma Fracalanza (2004):

No Brasil, as pesquisas em Educação Ambiental, realizadas em Cursos de Pós-Graduação de diferentes Instituições de Ensino Superior, têm sido produzidas em diferentes programas vinculados a diversas áreas de conhecimento, tais como: Agronomia; Arquitetura e Urbanismo; Biologia (especialmente Ecologia); Ciências Sociais; Direito; Economia e Administração; Educação; Engenharias; Geologia ou Geociências; Geografia; História; Medicina e Saúde Pública; Veterinária.

Outro aspecto importante ressaltado foi que muitos trabalhos de pesquisa em Educação Ambiental são feitos por mestres e doutores de outras áreas do conhecimento, o que contempla uma das principais características da Educação Ambiental: estar presente em todas as áreas do conhecimento e níveis de educação, segundo preceitua o ordenamento jurídico, ou seja, a Política Nacional de Educação Ambiental, Lei no 9795/99, em consonância com a Constituição Federal Brasileira de 1988 (CAPORLINGUA; COSTA, 2011).

A questão da aceitação e inserção da produção científica em EA, fruto do processo de conhecimento nascido nas diferentes áreas do conhecimento, foi apontada como uma dificuldade enfrentada pelos pesquisadores de EA, pois os artigos produzidos nem sempre são aceitos pelas revistas fora da área da Educação, tampouco são considerados relevantes para os indicadores de avaliação de cursos de Pós-Graduação de áreas outras que não a Educação.

Desse modo, foi salientada a necessidade de buscar a união, o compromisso e a participação do grupo de educadores ambientais a fim de obter força por meio do pensar e do fazer coletivo, promovendo, inclusive, melhor inserção 
política junto aos órgãos governamentais de gestão. Notadamente, a extinção e a criação de áreas em que está inserida a pesquisa da pós-graduação brasileira, conforme vem ocorrendo, fazem com que, em decorrência da necessidade de realocação dos cursos, haja sérios problemas de ordem estrutural, o que reflete no processo de produção do conhecimento.

Os problemas ambientais, aliados à reflexão sobre as complexas relações políticas, econômicas, sociais e culturais, envolvem, de modo integrado, pesquisadores cada vez mais preocupados com questões norteadoras da crise pela qual passa a humanidade. Nesse contexto, a EA torna-se essencial para a transformação e deve estar presente em todos os espaços educativos, de forma interdisciplinar e transversal. Ademais, a incorporação da EA às políticas públicas revela a sua crescente importância como proposta de buscar refletir e intervir na realidade em que nos encontramos.

\section{A pesquisa em Educação Ambiental no PPGEA/FURG²}

O Programa de Pós-Graduação (PPGEA) da Universidade Federal do Rio Grande (FURG), ao longo de alguns anos e como único Programa de PósGraduação em Educação Ambiental stricto sensu do Brasil, vislumbra desafios e perspectivas em alcançar a sua proposta de constituição de educadores ambientais por meio da inserção da pesquisa na pós-graduação brasileira.

A EA brasileira tem se constituído como um campo de atividade científica da área educacional, mas ultrapassando seus limites e dialogando com as mais diversas áreas de conhecimento. Reigota (2005) atribui uma singularidade à atividade científica da EA, a qual está profundamente relacionada com os sujeitos que buscaram e criaram espaços para a produção de conhecimento nessa área.

$\mathrm{Na}$ história do PPGEA, os professores orientadores possuem doutorado em diversas áreas: Educação (predominante), Ciências da Educação, Educação em Ciências, Ciências Marinhas, Ciências do Movimento Humano, Informática na Educação, Psicologia, História, Sociologia, Filosofia, Filosofia da Enfermagem, Enfermagem, Letras, Direito e Ecologia. Atualmente, fazem parte do corpo docente três doutores em Educação Ambiental formados pelo próprio PPGEA, e a formação diferenciada dos professores, alunos, projetos, grupos de pesquisa, estrutura curricular e estágio-docência do programa contribui fortemente para a ambientalização da educação e dos currículos.

Ao verificar o estado da arte da pesquisa em EA, no período compreendido entre 1984 e 2002, Reigota (2007, p. 39) afirma:

O Programa de Pós-graduação em Educação Ambiental da Fundação Universidade Rio Grande, pela sua especificidade, é o que tem contribuído com maior quantidade de dissertações (41 até o final do levantamento), apresentando ampla e profícua variedade temática. 
Lorenzetti e Delizoicov (2007), ao considerarem a produção da pesquisa em EA por regiões e estados, localizaram as principais instituições de ensino que produzem sobre a temática EA e os dados demonstraram, novamente, a preponderância da produção do PPGEA/FURG em EA. Afirmaram ainda que o programa possui pesquisa consolidada, uma vez que, desde 1997, sistematicamente produz dissertações na área.

Interessante compreender que a pesquisa em educação ocorre a partir da produção do conhecimento sobre o processo educativo ambiental, o qual visa a problematização do meio ambiente de forma a abordar a complexidade das relações socioambientais e provocar a reflexão crítica e transformadora para a reconstrução da realidade.

Portanto, é tarefa da Educação Ambiental proporcionar e promover a ambientalização dos processos educativos nas mais diversas áreas e níveis de conhecimentos. Isso significa que "o foco da produção de conhecimentos não

2 O Projeto Pedagógico do PPGEA foi utilizado como fonte de referência (SCHIMDT, 2010).

sao os temas ampienta1s gerais, mas o processo equcatıvo voltado para a problematização do ambiente" (TOZONI-REIS, 2008).

Foi com essa intenção que o PPGEA teve sua origem em 1993, quando um grupo interdisciplinar de docentes deu início ao processo de organização do Mestrado em Educação Ambiental (MEA), tendo em vista a importância da EA perante a crise socioambiental. Salienta-se que a EA é tema de dissertações desde 1984, e a primeira tese de doutorado na área foi defendida no ano de 1989 na Universidade de São Paulo (REIGOTA, 2005).

À época da criação do MEA os seus fundamentos desenhavam-se para a formação de uma instância privilegiada de reflexão e de irradiação da concepção de EA, ou seja, formar, pelo ensino e pesquisa, educadores que logo a seguir serão, por sua vez, "polos" de promoção de EA no sistema escolar. No mesmo sentido, atuar como instância "formadora de opinião pública reflexiva" através das atividades de pesquisa, extensão e divulgação (em especial mediante publicações e a utilização dos meios de comunicação) desenvolvidas pelo seu corpo docente e/ou discente.

Inicialmente, o programa foi pensado a partir de dois campos do conhecimento: Educação e Meio Ambiente, retratando no seu interior a dicotomia presente nessa construção, em que se tinham professores conhecedores da Educação e professores conhecedores das Ciências Biológicas, especialmente do meio ambiente e da oceanologia. (MOLON, 2008, p. 79). 
A consolidação da pesquisa, no decorrer dos anos, possibilitou, em 2006, a constituição da primeira turma no nível de doutorado. Assim, o PPGEA passou a incluir em seu estatuto a formação de doutores em EA. O Curso de Doutorado agregou à formação de acadêmicos a importância da pesquisa como veículo de aprimoramento da qualidade de vida ante as premências de um século que se iniciou sob a necessária égide da ética, da solidariedade e da integridade do ser humano.

O PPGEA possui apenas uma área de concentração: Educação Ambiental. Apresenta atualmente as seguintes linhas de pesquisa, que se complementam e se entrelaçam à medida que as pesquisas em EA são produzidas:

- Fundamentos da Educação Ambiental (FEA): aborda os fundamentos históricos, antropológicos, sociológicos, filosóficos (éticos e epistemológicos) da EA, pois são importantes na definição e na busca de mudanças de valores, conhecimentos, habilidades e comportamentos almejados pela EA na transformação da crise socioambiental;

- Educação Ambiental: Ensino e Formação de Educadores(as) (EAEFE): investe no desenvolvimento profissional dos pesquisadores em EA e busca a superação da dicotomia entre formação inicial e continuada e a articulação entre processo de ensino-aprendizagem e sua inserção no contexto sócio-histórico-cultural; discute a formação teórica, crítica e reflexiva nos contextos educativos que constituem os saberes da docência, as redes da aprendizagem e a formação de professores educadores ambientais;

- Educação Ambiental Não Formal (EANF): estuda as questões socioambientais nos campos não formais e informais da EA; enfatiza a dimensão ético-estética, a diversidade e alteridade dos grupos sociais, as relações entre a EA, os gêneros, as gerações humanas em todas as suas idades, o desenvolvimento humano e sistêmico, a compreensão da interligação dos espaços ambientais, da saúde coletiva e da qualidade de vida dos sujeitos e das instituições e organizações sociais; busca a construção coletiva de sociedades sustentáveis e utopias concretizáveis.

O PPGEA tem como principais objetivos: formar docentes pesquisadores capazes de contribuir para a produção de conhecimentos e sua transformação no campo da EA; criar condições que oportunizem a pesquisa e a teorização no campo da EA em suas múltiplas dimensões; possibilitar um ambiente que acolha a reflexão crítica coletiva sobre a prática e as teorias pedagógicas; contribuir para a qualificação da Educação Brasileira através do aprofundamento de estudos, do desenvolvimento de pesquisas e da produção de teorias que concorram para o avanço do saber e fazer educativos; contribuir para a consolidação de uma produção científica que aporte uma visão mais bem integrada do conhecimento.

Logo, a proposta do PPGEA consiste na formação de educadores ambientais nas mais diversas áreas do conhecimento, isto é, profissionais que 
tenham como preocupação: aprofundar a compreensão crítica da atual crise socioambiental no Brasil e no mundo; explorar alternativas teórico-práticas superadoras da referida crise; fundamentar a elaboração de propostas pedagógicas capazes de contribuir para a formação de cidadãos críticotransformadores da crise; focalizar a situação socioambiental regional e o papel que cabe à Educação; pesquisar na área da EA, buscando identificar problemas e propor soluções dentro de sua área de conhecimento e atuação; agir como elemento de reflexão e geração de propostas em matéria de EA como fator fundamental para a sustentabilidade.

\section{O educador ambiental no contexto da pesquisa}

A pesquisa em EA e o papel do educador ambiental no contexto da atualidade denotam a importância da formação de educadores ambientais que possam atuar e instaurar processos de transformação diante da inexorável fragilidade do planeta diante de uma crise socioambiental que o assola diuturnamente.

O educador ambiental precisa atribuir prioridade à
interdisciplinaridade como forma de produzir
conhecimento, e tentativa de estabelecer a
complementaridade no campo científico fragmentado, mas
sem renunciar ao rigor científico e ao debate consistente e
crítico da comunidade científica. A educação ambiental se
faz realidade, mas combinando princípios com práticas e
pesquisas empíricas. Cabe ao educador ambiental atentar
para o nexo e as respectivas distinções entre, de um lado, o
real/fatual, as práticas e os processos sociais, os conflitos, a
solidariedade; de outro, o dever ser, os ideais, os
enunciados, as representações sociais, os discursos, os
documentos ou planejamentos. (SCHIMIDT, 2010).

O PPGEA, desde a sua criação, vem desenvolvendo ações de pesquisa, ensino e extensão comprometidas com a produção e divulgação do conhecimento e com a formação de educadores ambientais, tecendo uma rede de informações gerais e específicas que, de variadas maneiras, têm demonstrado uma pertinente inserção social.

As dissertações e teses produzidas no PPGEA (em 2008 foi defendida a primeira tese em Educação Ambiental) tratam de temáticas relacionadas ao ambiente regional com fortes repercussões no contexto global. Entre os problemas que têm sido identificados e tratados pelo programa destacam-se: conceitos teórico-epistemológicos da EA, degradação ambiental, poluição, gestão dos recursos naturais, formação de professores, currículo, constituição de 
educadores ambientais, fatores e mecanismos de situações de risco e proteção social, exclusão social e saúde ecossistêmica (SCHMIDT, 2010).

Até a data do VI EPEA foram defendidas 233 dissertações e 20 teses, distribuídas ao longo dos anos, conforme se percebe por meio de gráfico (Gráfico 1) e tabela (Tabela 1) a seguir, relativos à produção da pesquisa no PPGEA/FURG.

\section{Curso de Mestrado e de Doutorado do PPGEA}

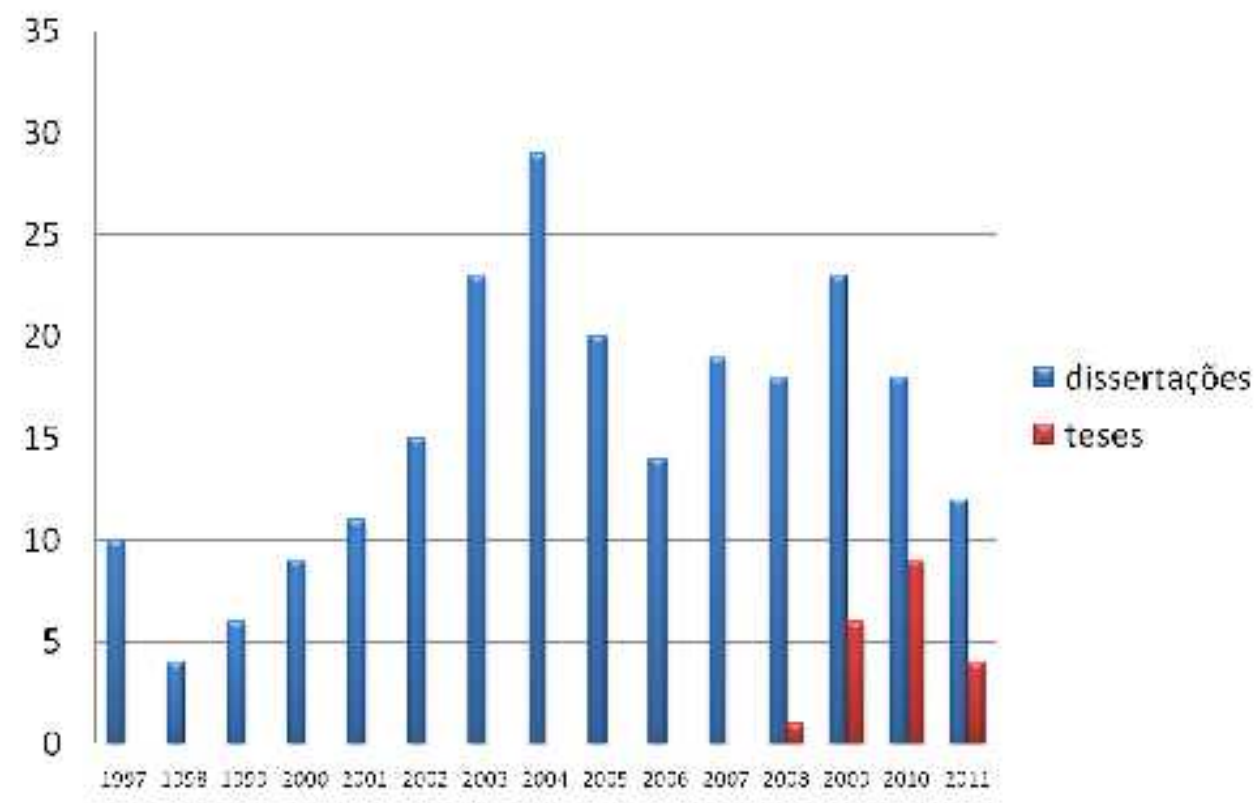

Gráfico 1. Produção de teses e dissertações desde a criação do PPGEA/FURG.

\begin{tabular}{|c|c|c|}
\hline ANO & DISSERTAÇÕ̃ES & TESES \\
\hline 1997 & 10 & \\
\hline 1998 & 04 & \\
\hline 1999 & 06 & \\
\hline 2000 & 09 & \\
\hline 2001 & 11 & \\
\hline 2002 & 15 & \\
\hline 2003 & 23 & \\
\hline 2004 & 29 & \\
\hline
\end{tabular}




\begin{tabular}{|c|c|c|}
\hline $\mathbf{2 0 0 5}$ & 20 & \\
\hline $\mathbf{2 0 0 6}$ & 14 & \\
\hline $\mathbf{2 0 0 7}$ & 19 & 01 \\
\hline $\mathbf{2 0 0 8}$ & 18 & 06 \\
\hline $\mathbf{2 0 0 9}$ & 23 & 09 \\
\hline $\mathbf{2 0 1 0}$ & 18 & 04 \\
\hline $\mathbf{2 0 1 1}$ & 12 & \\
\hline
\end{tabular}

Tabela 1. Produção de teses e dissertações desde a criação do PPGEA/FURG.

A abordagem dos conteúdos nas disciplinas, leituras dirigidas e práticas de pesquisa que compõem os cursos de Mestrado e Doutorado converge para a ênfase na reflexão e ação sobre o meio ambiente, desencadeando atividades de EA que extrapolam as discussões em sala de aula, atingindo grupos sociais de diferentes expressões culturais e escolas da região, e que são promovidas por educadores ambientais provenientes de diversas áreas do conhecimento.

O contexto de atuação do educador ambiental está previsto na Constituição Federal, Art. 225, inciso VI, regulado pela Política Nacional de Educação Ambiental - PNEA (Lei 9.795/99) -, a qual, especificamente no Art. $3^{\circ}$, define as incumbências em EA, delegando responsabilidades pela sua aplicação ao Poder Público, instituições educativas, órgãos integrantes do Sistema Nacional de Meio Ambiente (Sisnama), meios de comunicação de massa, empresas, entidades de classe, instituições públicas e privadas e à sociedade como um todo. Por sua vez, o Decreto $n^{\circ} 4.281 / 2002$, ao regulamentar a PNEA, demonstra a ampla abrangência dos contextos de ação do educador ambiental pela determinação, em seu Art. $6^{\circ}$, de que sejam criados, mantidos e implementados programas de EA integrados a todos os níveis e modalidades de ensino; às atividades de conservação da biodiversidade, de zoneamento ambiental, de licenciamento e revisão de atividades efetivas ou potencialmente poluidoras, de gerenciamento de resíduos, de gerenciamento costeiro, de gestão de recursos hídricos, de ordenamento de recursos pesqueiros, de manejo sustentável de recursos ambientais, de ecoturismo e melhoria de qualidade ambiental; às políticas públicas, econômicas, sociais e culturais, de ciência e tecnologia de comunicação, de transporte, de saneamento e de saúde; aos processos de capacitação de profissionais promovidos por empresas, entidades de classe, instituições públicas e privadas; a projetos financiados com recursos públicos; e à Agenda 21.

Assim, os profissionais estarão capacitados para exercer atividades de docência e/ou pesquisa em instituições educacionais, além de poderem atuar em 
organismos sociais e empresariais que demandem conhecimentos relacionados à EA.

Esse conjunto de atores e ações, sintetizado na Figura $1 \mathrm{em}$ função das categorias EA formal, EA não formal e informal, constitui o amplo contexto de ação do educador ambiental e demonstra o desafio da formação de profissionais em EA que estejam capacitados para atuar com os diferentes públicos (tempos) e realidades socioambientais (espaços) (SCHIMIDT, 2010).

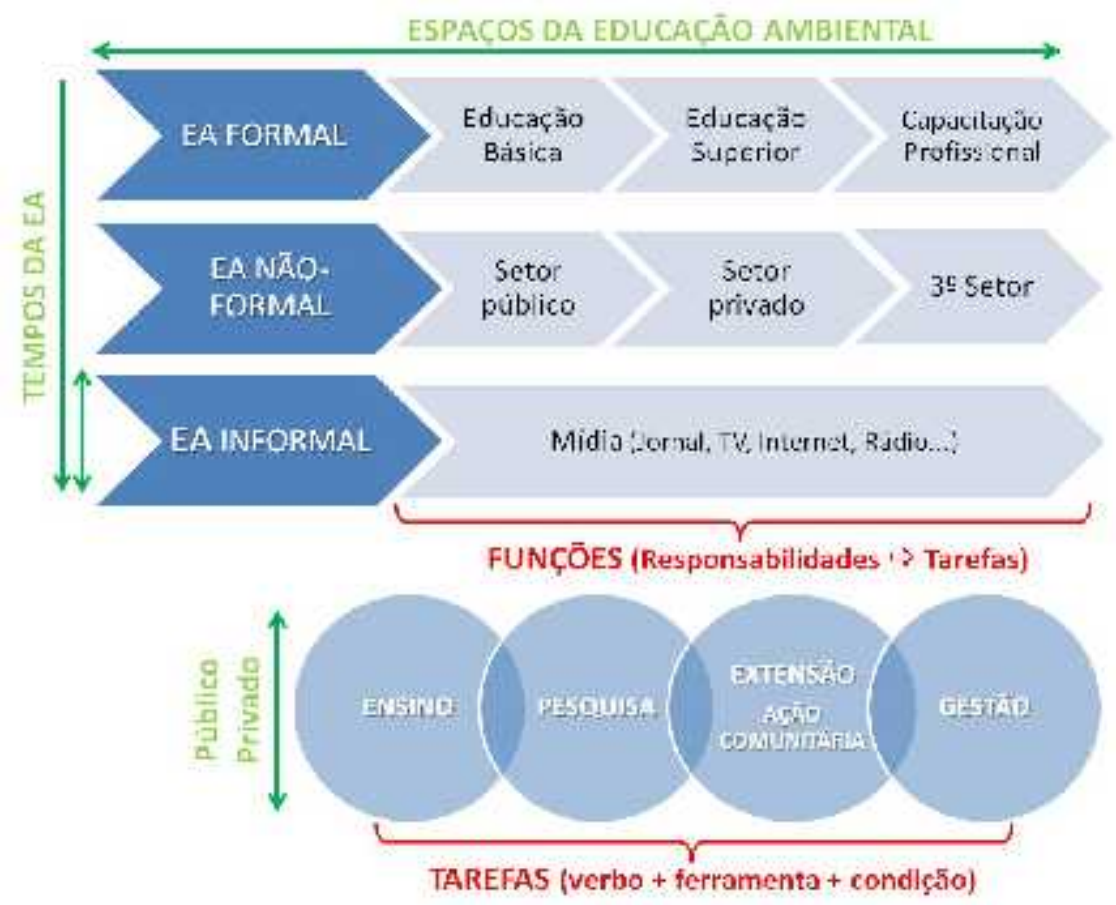

Figura 1. Contexto de ação dos educadores ambientais e os espaços e tempos de atuação profissional.

Com base nos principais contextos de ação assumidos da EA - ensino, pesquisa, extensão/ação comunitária e gestão -, tratou-se de definir no âmbito do PPGEA o "Perfil de Ação Profissional" do educador ambiental. Logo, uma vez que esteja estabelecido o conjunto de atividades previstas para a atuação de um profissional em seus possíveis setores, é possível propor um currículo que contenha e desenvolva adequadamente os conhecimentos, habilidades e atitudes necessárias ao alcance dos objetivos. Isso permite que haja disciplinas ou módulos voltados à esperada atuação do profissional que se deseja formar. Cada componente de uma disciplina (ou mesmo ela própria) pode ser revisto sempre que forem detectadas evoluções da ação profissional, o que é muito comum no sistema socioambiental em que vivemos (SCHMIDT, 2010). 
Portanto, o perfil do egresso do PPGEA também é determinado pela inserção da pesquisa, a partir de um amplo conjunto de atores e ações na articulação entre as linhas de pesquisa de forma a constituir o contexto de atuação do educador ambiental.

O processo de formação dos educadores ambientais é complexo em virtude dos pressupostos teóricos, filosóficos, éticos, políticos e socioculturais que fundamentam a área da EA.

\begin{abstract}
Além disso, é necessário conhecer e dialogar com os autores e interlocutores, com as publicações de livros, das revistas e periódicos da área. É preciso entender as relações entre a EA e a Educação e entre a EA e as demais áreas do conhecimento; bem como conhecer os documentos e leis, as políticas públicas em EA. Ainda, acompanhar os eventos promovidos, participar dos eventos, do GT da ANPEd e das ANPEds Regionais. Cabe destacar a importância da presença e da participação de educadores ambientais no GT EA na ANPEd Nacional e na ANPEd-Sul (MOLON, 2008, p. 73).
\end{abstract}

Assim, a pesquisa em EA e o papel do educador ambiental no contexto da atualidade denotam a importância da formação de educadores ambientais que possam atuar e instaurar processos de transformação diante da inexorável fragilidade da transformação oriunda de uma crise socioambiental que diuturnamente assola o planeta.

\title{
Considerações finais
}

A pesquisa brasileira em EA permite ações políticas e pedagógicas, uma vez que a EA é uma educação política com o compromisso de consolidar uma sociedade democrática em busca da efetivação da cidadania. A pretensão da EA de formar cidadãos críticos e participativos é no sentido de prepará-los para a transformação necessária.

A cidadania confere ao cidadão a participação na vida política e consequentemente o acesso efetivo aos direitos fundamentais. No entanto, é necessário que o cidadão participe das relações fazendo valer seus direitos de modo a perceber que a cidadania se constrói no movimento da realidade socioambiental e para tanto é preciso o conhecimento gerado pela Educação Ambiental transformadora, a fim de proporcionar escolhas e assim exercer direitos (CAPORLINGUA; COSTA, 2011).

$\mathrm{O}$ aumento dos trabalhos de pesquisa em EA revela a existência de um grupo crescente de pesquisadores em EA no Brasil preocupados com a 
realidade e o futuro do planeta. É necessário compreender a relevância do aumento dessa produção, principalmente quanto à crescente contribuição para a formação crítica de cidadãos que diuturnamente vivem problemas de interesse difuso e coletivo.

Como resultado desse processo, tem-se a perspectiva do surgimento de novas linhas de pesquisa, bem como processos de ensino-aprendizagem e métodos de investigação. É importante ressaltar que o EPEA simboliza a ampliação da dimensão política e a consolidação do campo de pesquisa em EA no Brasil.

Assim, o EPEA compartilha pioneirismo e repercussão como espaço que representa a pesquisa em EA na pós-graduação brasileira e confere determinação para que as investigações se mostrem em diálogos de luz e caminhos harmoniosos em prol de um espaço-tempo que contemple esperanças transformadoras a partir da EA.

\section{Referências}

CAPORLINGUA, Vanessa Hernandez; COSTA, César Soares da. A inserção da educação ambiental no direito: horizontes interdisciplinares. Contribuciones a las Ciencias Sociales, ago. 2011. Disponível em: <http://www.eumed.net/rev/cccss/13/hcsc.html>. Acesso em: 12 out. 2011.

CARVALHO, Isabel Cristina de Moura; FARIAS, Carmen Roselaine de Oliveira. Um balanço da produção científica em educação ambiental de 2001 a 2009 (Anped, Anppas e EPEA). Revista Brasileira de Educação, v. 16, n. 46, p. 119-134, jan./abr. 2011.

Educação ambiental crítica: nomes e endereçamentos da educação. In: LAYRARGUES, Philippe Pomier (Coord.). Identidades da educação ambiental brasileira. Brasília: MMA, DEA, 2004. p. 13-24.

CASCINO, Fábio. Educação ambiental: princípios, história e formação de professores. São Paulo: SENAC, 2003.

CAVALARI, Rosa Maria Feiteiro; SANTANA, Luiz Carlos; CARVALHO, Luiz Marcelo de. Concepções de educação e educação ambiental nos trabalhos do I EPEA. Pesquisa em Educação Ambiental, v. 1, n. 1, p. 141-173, jul./dez. 2006.

FRACALANZA, Hilário. As pesquisas sobre educação ambiental no Brasil e as escolas: alguns comentários preliminares. In: TAGLIEBER, José Erno; GUERRA, Antonio Fernando Silveira (Org.). Pesquisa em educação ambiental: pensamentos e reflexões de pesquisadores em educação ambiental. Pelotas: Ed. Universitária/UFPel, 2004. p. 55-77.

GONZÁLEZ GAUDIANO, Edgar; LORENZETTI, Leonir. Investigação em educação ambiental na América Latina: mapeando tendências. Educação em Revista, Belo Horizonte, v. 25, n. 3, p. 191-211, dez. 2009. 
LORENZETTI, Leonir; DELIZOICOV Demétrio. A produção acadêmica brasileira em educação ambiental. Pré-publicação - V Congreso CEISAL - Bruxelas, 11 -14 de abril de 2007. Disponível em: <http://www.reseau-ameriquelatine.fr/index.php?act=busc\&result=actu\&multi=lorenzetti $>$ Acesso em: 19 jul. 2011.

LORENZETTI, Leonir; DELIZOICOV, Demétrio. Uma análise da pesquisa em educação ambiental desenvolvida na área de ciências humanas. Anais do VII Seminário de Pesquisa em Educação da Região Sul: Pesquisa em Educação e inserção social. ANPEdSul, Univali: Itajaí, 2008.

MOLON, Susana Inês. Formação em Educação Ambiental: um olhar sobre o PPGEA/FURG. Rev. Eletrônica Mestr. Educ. Ambient, v. especial, p. 71-86, dez. 2008. Disponível em: <http://www.remea.furg.br/edicoes/volesp08/art6vesp.pdf>. Acesso em: 30 set. 2011.

REIGOTA, Marcos. O estado da arte da educação ambiental no Brasil. In: ENCONTRO DE PESQUISA EM EDUCAÇÃO AMBIENTAL, 3., 2005, Ribeirão Preto, SP. Mimeo.

SATO, Michèle; CARVALHO, Isabel Cristina de Moura (Org.). Educação ambiental: pesquisa e desafios. Porto Alegre: Artmed, 2005.

SCHIMDT, Elisabeth Brandão et al. Projeto pedagógico do Programa de PósGraduação em Educação Ambiental: aprovado pelo colegiado do PPGEA e, 17 de dezembro de 2009. Rio Grande: FURG, 2010.

TOZONI-REIS, Marília Freitas de Campos. Pesquisa-ação em Educação Ambiental. Pesquisa em Educação Ambiental, Ribeirão Preto, v. 3, n. 1, p. 155-169, jun. 2008. Disponível em:

<http://www.revistasusp.sibi.usp.br/scielo.php?script=sci_arttext\&pid=S1980-

11652008000100009\&lng=pt\&nrm=iso >. Acesso em: 15 abr. 2011.

2004.

Educação ambiental: natureza, razão e história. São Paulo: Autores Associados,

TRAJBER, Rachel; MENDONÇA, Patrícia Ramos (Org.). O que fazem as escolas que dizem que fazem educação ambiental? Brasília: SECAD; UNESCO, 2006. (Coleção Educação para Todos, Série Avaliação, n. 6, v. 23). Disponível em: <http://unesdoc.unesco.org/images/0015/001545/154576por.pdf>. Acesso em: 12 out. 2011.

Artigo recebido em 13/08/2012

Artigo aprovado em 13/11/2012 